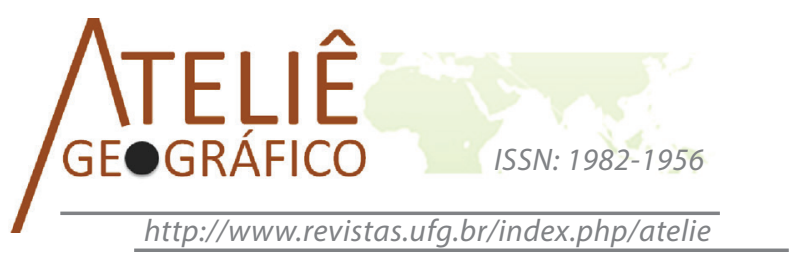

\title{
Tensiones entre las imágenes didácticas y el arte
}

\section{Tensões entre as imagens didáticas e a arte}

Exploring the tensions of teaching images and art

\author{
Verónica Carolina Hollman \\ Universidad de Buenos Aires \\ vhollman@gmail.com
}

\author{
Malena Malena Mazzitelli Mastricchio \\ Universidad Nacional de la Plata \\ mastricchiomalena@gmail.com
}

\begin{abstract}
Resumen
Proponemos revisar, desde una perspectiva histórica, la aparente nitidez de la separación entre las imágenes utilizadas en la enseñanza y el arte. Nos interesa identificar las condiciones que hacen visible una imagen en las culturas escolares para analizar de qué modo algunas de ellas son consideradas didácticas y otras, artísticas. Identificamos y analizamos tres condiciones de visibilidad: los soportes aceptados por las culturas escolares para hacer de las imágenes objetos de uso escolar, los contextos de visualización y las convenciones que moldean, de manera más o menos explícita, los modos de mirar las imágenes. El esfuerzo analítico tiene como horizonte en devenir la exploración de los aportes que puede hacer el arte para que el encuentro con las imágenes en las culturas escolares contemporáneas sea más rico, diverso y sobre todo nos inquiete y de algún modo, también nos afecte.
\end{abstract}

Palabras clave: imágenes; soporte; contexto; convenciones

\section{Resumo}

A proposta deste artigo é discutir a aparente claridade na separação entre ensino e arte tomando como objeto de analise as imagens com o intuito de identificar, desde uma perspectiva histórica, as condições que, nas culturas escolares, dão visibilidade às imagens e que as tornam didáticas ou artísticas. Três condições de visibilidade são identificadas e analisadas: o suporte material aceito para fazer das imagens objetos de uso escolar, os contextos de visualização e as convenções (explícitas ou 
implícitas) que configuram os modos de olhar as imagens. Este esforço analítico tem como horizonte em devir a exploração dos diálogos entre arte e ensino para abrirmos a outros encontros com as imagens nas culturas escolares contemporâneas. Palavras chave: imagens; suporte; contexto; convenções

\begin{abstract}
From an historical approach, this article focuses on the conditions under which images become schooling objects. By looking at the practices and conditions that support the categorization of images as a teaching device we aim to discuss the traditional distinction between didactic and artistic images. Three conditions that define images as schooling objects are identified and analyzed: the material display of images used at schools, the contexts of visualization and the conventions that shape the ways of seeing. We hope to offer some keys to promote other ways of approaching to images at contemporary schooling practices.
\end{abstract}

Keywords: images; displays; contexts; conventions

\title{
Introducción
}

En el libro Picturing science, producing art, publicado ya hace algunos años, Caroline Jones y Peter Galison proponen analizar las condiciones a partir de las cuales los objetos se vuelven visibles en una cultura y los modos en que esas visibilidades se caracterizan como científicas o artísticas. Aquel interrogante se nos presenta como una brújula para pensar las tensiones (y también las relaciones no siempre conflictivas) entre las imágenes didácticas - aquellas utilizadas a la hora de enseñar, es decir con un propósito educativo- y el arte -ese conjunto de creaciones visuales, sonoras, corporales que permite expresar ideas, percepciones, emociones.

A pesar que el título de este trabajo delinea una nítida separación entre arte y enseñanza (que evoca la distancia que suele establecerse entre el arte y la ciencia), proponemos precisamente revisar ese límite desde una perspectiva histórica tomando como objeto de análisis las imágenes. Una línea divisoria que por momentos se presenta con nitidez y que sin embargo, no deja de ser lo suficientemente problemática como para, al menos, hacernos algunos interrogantes al respecto. Nos interesa, retomando el desafío de Jones y Galison (1998), identificar las condiciones que en nuestras culturas escolares hacen visible una imagen. Indagaremos de qué modo determinadas imágenes se caracterizan como (o se vuelven) didácticas o artísticas, haciendo un recorte de carácter analítico pues solo nos referiremos a las expresiones visuales del campo de las artes. El esfuerzo analítico tiene como horizonte en devenir la exploración de los aportes que puede hacer el arte para que el encuentro con las imágenes en las culturas escolares contemporáneas sea más rico, diverso y sobre todo nos inquiete y de algún modo, también nos afecte. 


\section{Una paleta de grises. El soporte de la imagen y su contexto de visualización}

Proponemos iniciar este recorrido con un desafío a los lectores: arriesgarse a establecer una correspondencia entre la descripción que sigue y el tipo de imagen a la cual ella podría estar aludiendo:

Que alteran la pureza del aire porque son depósitos de gérmenes.

Que colocadas constantemente a la vista de los alumnos que se han acostumbrado a verlas sin mirarlas, no llenan cuando se le presentan para los fines de la enseñanza, el objeto propuesto.

Que no ofrecen el modelo de simetría y de buen gusto, porque su colocación por lo general, no ha sido presidida por persona inteligente y porque las necesidades de las clases obligan a retirar algunas.

Que se destruyen sin ser usadas, por el viento y la frecuente remoción. (Juan Vedía, 1902: p.946)

Tal vez, usted lector, imaginó que este pequeño fragmento aludía a una escultura, a una fotografía un poco atrevida o incluso a una pintura surrealista. Cualquiera de estos escenarios guardan bastante distancia con el texto en cuestión: escrito para una audiencia de profesores y maestros en la Argentina de principios del siglo XX, se refiere a los mapas colgados en las paredes de las aulas. Si todavía existiera alguna duda, y sin por ello pretender desalentar su imaginación, resta señalar que la descripción es un fragmento de un artículo titulado Los mapas. Estampas y demás objetos de enseñanza. Sí, mapas: una imagen que el sentido común identifica como técnica, objetiva, precisa, de síntesis. Todos ellos, atributos que podrían definir o caracterizar una imagen didáctica. En efecto, las imágenes didácticas suelen ser claras, concisas, recurrir a convenciones gráficas y a un vocabulario comprensible. Incluso se admite cierto derecho a la inexactitud o la imprecisión si con ello se privilegia la intención pedagógica. Las imágenes didácticas parecieran gozar de una aceptación natural en el contexto escolar. Sin embargo, y aunque en la actualidad esto pueda provocar cierta sorpresa, la cita revela que la incorporación de las imágenes en las prácticas de enseñanza fue un proceso que suscitó incertidumbre, inquietud y sobre todo controversia en el campo educativo.

Tres años más tarde, en la misma revista, se publicaba una fotografía de una escena escolar que pareciera intencionalmente montada para la toma fotográfica (Figura 1). En la fotografía, el salón de clase está cubierto de láminas entre las que se destacan dos mapas que hacen visible el territorio de la nación. Una niña simula el acto de trazar a mano alzada otro mapa en un pizarrón móvil, tal vez intentando con este gesto sugerir a los maestros y los profesores, lectores de esta publicación, la colaboración de las imágenes en la tarea de enseñar y de aprender.

Si bien la exposición de mapas en las paredes de los salones de clase es una invención que se remonta al último tercio del siglo XIX (Jacob, 2006), la proliferación de mapas que encontramos en el salón de clase de la fotografía es sintomática de la idea sostenida en la época sobre el ineludible uso de este registro visual en el estudio de la disciplina, como lo indica la autora de un libro escolar publicado en 1875: 
Es muy esencial para que el niño no olvide este estudio, que está enteramente sujeto á la memoria, que las lecciones sean tomadas con el mapa delante y que al dar al niño la definición de un lago, montaña, etc., sepa distinguirlos en la carta, igualmente las ciudades y Estados, haciéndoles notas en éstas las circunstancias que se reúnen para hacerles notables, pues esto ayuda á la memoria, que con facilidad olvida tantos nombres, pero que generalmente se le quedan impresas algunas de estas circunstancias de un país (Villarino de Carril María, 1875).

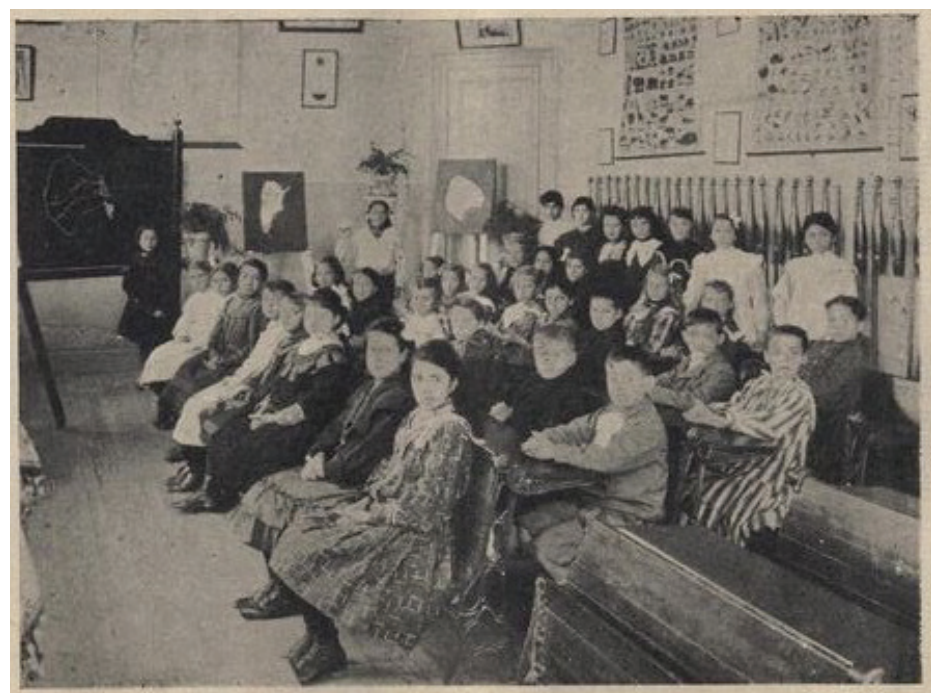

Figura 1. Los mapas en una escena escolar de principios de siglo XX en Argentina. Fonte: Torres (1905)

La certeza sobre la necesidad de acudir al mapa en la enseñanza de la geografía se presta a cierta ambigüedad en el enunciado el mapa delante. Incluso con las tecnologías de visualización disponibles en una escuela de aquella época, ciertamente más acotadas si las comparamos con las actuales, el mapa delante podría hacer referencia a una variada gama de alternativas entre las cuales cabría mencionar el mapa reproducido en un libro escolar o en un atlas, expuesto en una pared, dibujado en la pizarra o reproducido en una diapositiva de vidrio y proyectado en una pantalla o en una pared del salón de clase. Todos estos soportes de visualización de los mapas y de otros registros visuales, ya aceptados en las culturas escolares contemporáneas, no se juzgaban igualmente apropiados para la enseñanza a principios del siglo XX. Así por ejemplo, el atlas escolar, una colección ordenada de mapas, se valoraba como un aliado imprescindible para acompañar la lectura y el estudio del manual escolar: a medida que el alumno leía el texto escolar debía mirar los mapas, reproducidos en un volumen dedicado con exclusividad a este registro visual, y encontrar en ellos la información y los datos indicados en el texto escolar. Otro soporte apreciado para el uso del mapa en el contexto escolar era el cuaderno de 
ejercicios cartográficos: un volumen que reproducía en sus páginas croquis simplificados y series de mapas para completar.

Los mapas, como imagen didáctica, no solo debían "reunir en forma clara y exacta las principales nociones geográficas, que forman la base general de la cultura de la juventud" (Anesi, 1943: 70), sino también adoptar una materialidad ajustada - y conferida por determinados soportes- a las culturas escolares. Una materialidad que, como intentaremos argumentar, de algún modo participa, interviene y modela los modos de mirar. En efecto, con sus especificidades, tanto el atlas como el cuaderno de ejercicios cartográficos compartían la orientación hacia un modo de mirar los mapas que podríamos caracterizar como más regulado, organizado, sistematizado e individual. En este sentido, la identificación de los soportes propicios para hacer del mapa un objeto de uso escolar, un "recurso" didáctico, arroja algunas claves para pensar las condiciones que el soporte físico impone en el acto de mirar este y otros registros visuales, particularmente en el acto de enseñar a mirarlos. Es decir, el soporte que inscribe la imagen participa como una de las condiciones de visibilidad a partir de las cuales ella se vuelve didáctica.

La fotografía de la Figura 1 brinda una clave más: paradójicamente el objeto de la mirada de los alumnos es la cámara y no precisamente las láminas colgadas en las paredes sugiriendo que los mapas exhibidos en las láminas se miran de otro modo, un mirar repetitivo pero también más efímero y casual. Un mirar que podría concebirse como "más apropiado" para el visitante de una galería de arte. No resulta extraño, entonces, que la exposición del mapa en las paredes escolares haya provocado controversias en torno a la incidencia que ejercía este soporte en el acto de mirar y en el aprendizaje: desde posturas que sostenían que este modo de exhibir los mapas debilitaba su potencia al momento de utilizarlos, pues ellos dejaban de llamar la atención, hasta posiciones que adjudicaban más poder a la imagen asegurando que su permanente exposición facilitaba la fijación gráfica de ciertas formas necesarias para el aprendizaje de las nociones geográficas ${ }^{1}$.

Los mapas de artistas como Vik Muniz o Mona Hatoum ${ }^{2}$ y la experiencia de mirarlos en otro contexto (colgados en la pared de una galería de arte y en diálogo con otras obras de estos artistas), nos invitan a preguntarnos qué tipo de observadores presupone la imagen en cada contexto de visualización. En el caso de la obra de Mona

1. Christian Jacob, para el caso de las escuelas de Estados Unidos, rastrea una argumentación de orden conceptual: se consideraba que la exposición vertical de los mapas podía traer aparejados errores conceptuales y por ello se recomendaba iniciar las lecciones de geografía con el trazado en el piso del Norte y el Sur con la finalidad de evitar que los alumnos, al ver los mapas expuestos verticalmente, pensaran que el Norte estaba "arriba" y el Sur "abajo" (Jacob, 2006: 93). En el caso argentino, y tomando como fuente la publicación El Monitor de la Educación Común, encontramos que una de las argumentaciones más utilizadas en contra de la exhibición de mapas en las paredes toma como base el higienismo: se explicaba que la permanente exposición de láminas alteraba la pureza del aire en las aulas. Desde una u otra argumentación, está claro que el soporte del registro visual -pared o piso- es el foco de la controversia.

2. Citamos aquí estos dos artistas, entre muchos otros que vienen utilizando el mapa, y de manera más o menos explícita intentan provocar otro modo de mirar el mundo, pues asistimos a dos muestras de sus obras realizadas durante el año 2015 en la ciudad de Buenos Aires. Sobre estas muestras véase Bertola (2015) y Wechsler (2015). 
Hatoum, se introducen al mapa elementos discordantes que alienan su uso más evidente y esto obliga al espectador a re-enfocar la mirada, a volver a mirar otros de los objetos cotidianos y a la vez extraños. El mapa de Vik Muniz, en la serie Imágenes de chatarra, supone un observador que al mirar esa amalgama de objetos desechados también acepta imaginar y delinear otras fronteras. La obra y el contexto de exposición estimulan a redibujar las fronteras que solemos considerar como fijas (Figura 2). En ambos casos, a través de diversas transgresiones al mapa -por los materiales, sus formas y también por su propia exhibición en una galería de arte- se propone revisar el mundo, nuestros modos de ordenarlo y también imaginarlo (de Diego, 2008).

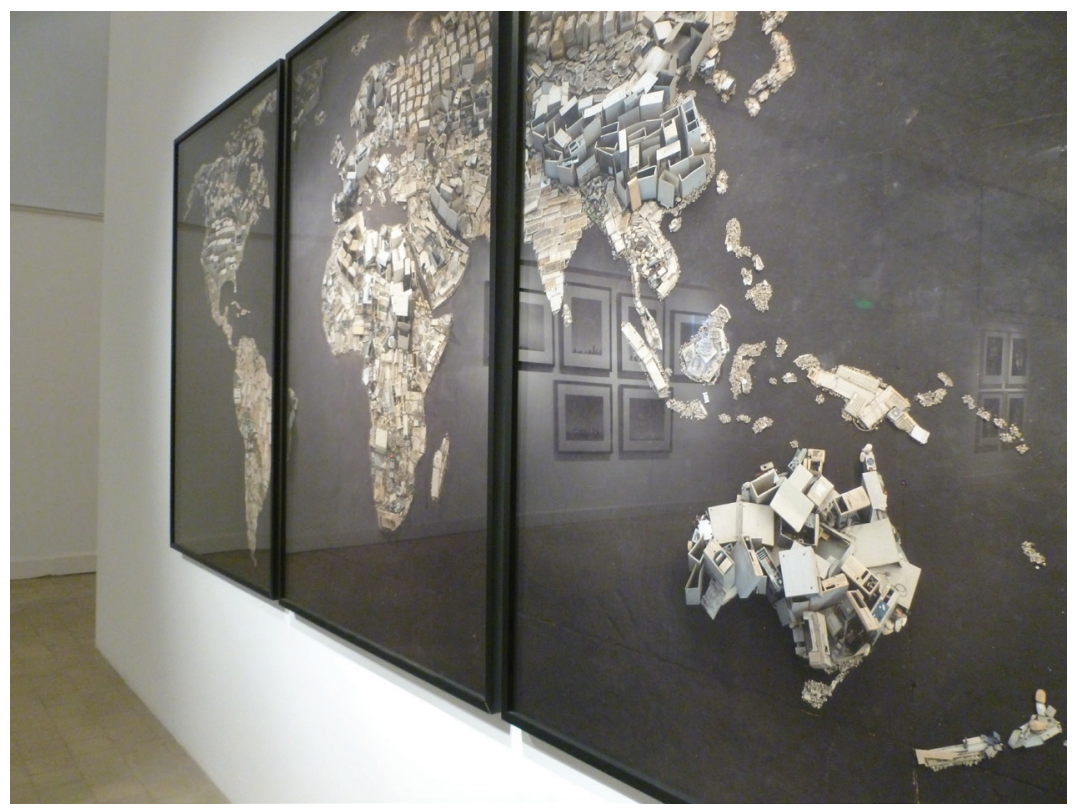

Figura 2. El mapa en un contexto "artístico".

Fonte: fotografía de las autoras, en Museo de la Universidad Nacional de Tres de Febrero. Vik Muniz. Buenos Aires. Septiembre 2015.

Un mapa expuesto en una galería de arte integra una colección de imágenes montadas con una idea que las articula. En ese contexto, el mapa supone un observador que deambula con su propio ritmo, que mira una serie de imágenes cuidadosamente seleccionadas para estimular diálogos entre ellas, y con disposición a sorprenderse/ extrañarse ante estos objetos dislocados en su contenido, en sus usos, en su finalidades. Dicho de otro modo, el uso de los mapas en contextos artísticos - ya no solo por su contenido- nos fuerza a mirar de otro modo esa imagen conocida aunque por un momento se vuelva extraña y hasta pueda lograr incomodarnos. La cultura escolar, en cambio, todavía supone un observador (alumno o profesor) que lejos de extrañarse o inquietarse ante una imagen (incluso una imagen que siempre miramos) cree saber precisamente lo 
que puede encontrar en ella. En otras palabras, las culturas escolares todavía atribuyen transparencia a las imágenes y como consecuencia, esperan mirarlas sin muchos rodeos. Tal vez aquí se establezca la principal tensión: el encuentro con las imágenes en los contextos artísticos habilita a quien mira tener más interrogantes que respuestas, más incertidumbres que certezas, a reconocer su condición de "formación facetada" (Giunta, 2011) que lo que se acepta las culturas escolares contemporáneas.

\section{Convenciones y cultura visual: imágenes científicamente artísticas y artísticamente científicas}

La Figura 3 reúne dos imágenes que nos permiten volver a discutir las fronteras entre las imágenes artísticas, las científicas y las didácticas. La primera (izquierda) es una acuarela y tinta sobre papel de 56 centímetros por 42 centímetros realizada por el pintor argentino Ernesto Pesce 3 , titulada "Mariana escala el Volcán Villarica" (2007). La segunda imagen (derecha) fue realizada por el naturalista alemán von Humboldt (17691859) en 1802 cuando ascendió al volcán colombiano el Chimborazo ${ }^{4}$, y fue publicada en la edición original de Essai sur la géographie des plantes $^{5}$, en 1807, en una hoja de 80 centímetros de alto por 40 centímetros de ancho (Zimmerer, 2011). Conociendo el perfil profesional de los autores y la audiencia que ellos imaginaron para sus trabajos, no dudaríamos en afirmar que la primera es una imagen artística y la segunda, una imagen científica. Sin embargo, estas imágenes resultan más híbridas si las miramos sin esas anteojeras que naturalizamos por una serie de convenciones disciplinares y estéticas actuales que intervienen en nuestro modo de mirarlas.

La acuarela de Pesce fue pensada desde el arte pero, no obstante ello, evoca un lenguaje gráfico usado actualmente por geólogos y geógrafos para representar la estructura interna de la tierra y las formas del relieve. Específicamente, su dibujo se parece mucho al bloque-diagrama, un tipo de imagen que tiene una larga tradición entre las maneras de representar las geoformas del paisaje que ha formado una parte crucial en los modos de concebir la disciplina geológica. Según Eduardo Martínez de Pisón y Juan Carlos Castañón Álvarez, Johann Wolfang Goethe (1749-1832) dio un gran impulso intelectual a este tipo de representación gráfica del relieve cuando se propuso ensayar en sus escritos "la posibilidad de realizar un modelo geológico que sea capaz de mostrar las entrañas de la tierra por debajo de la apariencia externa del relieve" (2005: 103). A pesar de este temprano interés, no fue sino hasta fines del siglo XIX que apareció en

3. Ernesto Pesce nació en Buenos Aires el 4 de abril de 1943. Desde el año 1968 participa en salones nacionales, provinciales y municipales, y también en exposiciones realizadas en países como Brasil, México, EEUU, España, Italia, Alemania, Taiwán, Polonia, Puerto Rico, Yugoslavia, Japón, Uruguay, Chile, Suiza, Cuba, India. Sobre la obra de Pesce, véase: http://www.todoslosartistas.org/artistas.php?artista=443

4. La importancia del ascenso al Chimborazo en la obra de Humboldt, según Pimentel (2003), radica en que allí Humboldt "proyecta todo su pensamiento visual para representar en una sola imagen su concepción de la unidad dentro de la diversidad". Véase Pimentel (2003) para un análisis simbólico del ascenso del naturalista al volcán Chimborazo.

5. Esta obra se considera fundacional de la moderna biogeografía y ecología (Zimmerer, 2011). 
los Estados Unidos el bloque diagrama ligado a una visión dinámica del paisaje ${ }^{6}$ en un sentido muy próximo al que se utiliza hasta nuestros días: los primeros bloques-diagrama fue realizados por Peale en 1872 del Monte Ellsworth y poco tiempo después, por G. K.Gilbert en 1876. Estos autores sentaron una tradición artístico-científica que luego fue retomada por el geógrafo Williams Morris Davis para proponer una explicación visual de su conceptualización del ciclo geográfico?
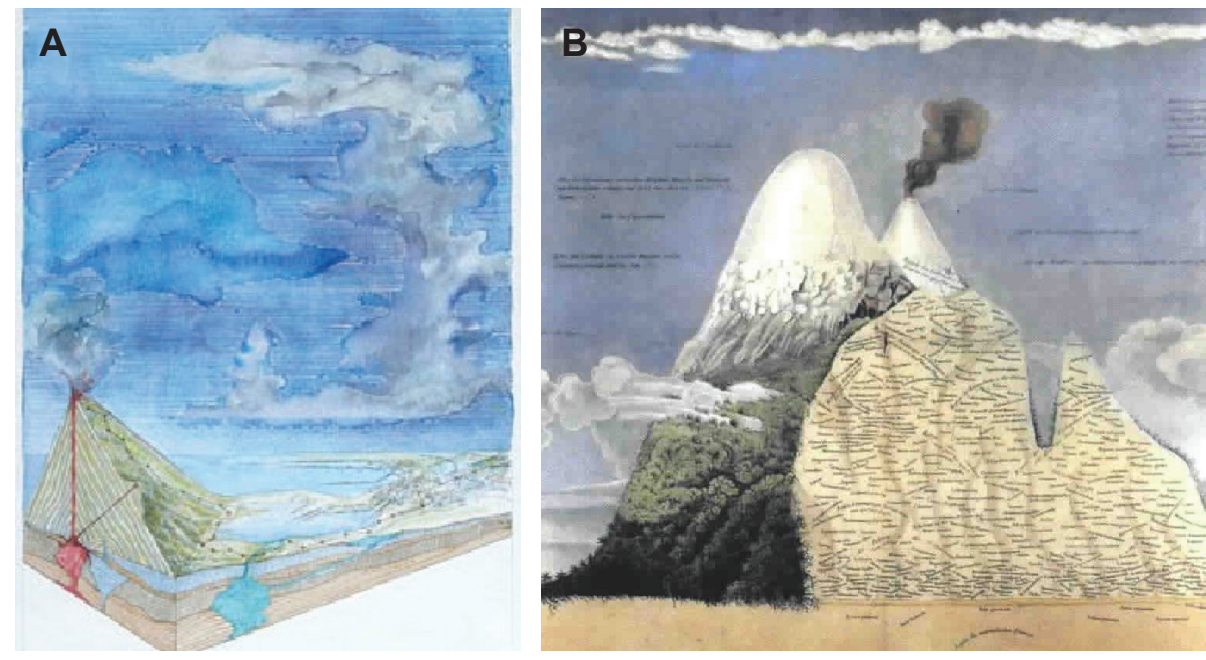

Figura 3. Imágenes científicamente artísticas/artísticamente científicas. Fig 3A. Mariana escala el Volcán Villarica, de Jorge Pesce (2007). 3B. Géographie des plantes équinoxiales: tableu physique des Andes e Pays voisins fondé sur des mesures exécutes, depuis le disième degré le latitude boréale jusqu' au dixième degré de latitude australe, pendant les années 1799, 1800, 1801, 1802 et 1803, A. von Humboldt (1807).

Para la realización de este tipo de figuras hay que seguir rigurosamente una serie de instrucciones matemáticas y de perspectivas que parecen alejar la representación de las subjetividades del sujeto que las realiza. Por ejemplo, en el clásico libro de Erwin Raisz de 1959 [1953] llamado Cartografía se describen los pasos para realizar este tipo de representaciones de manera tan esquemática que se tiene la sensación de que sólo hay que seguir una receta, en la que la creatividad no interviene. Sin embargo, recordemos que las artes plásticas también tienen un largo desarrollo teórico respecto de las proyecciones y las perspectivas.

La segunda imagen muestra en corte transversal desde la costa del Océano Pacífico hasta la cumbre del Chimborazo (6.212 metros) considerada a mediados del siglo XIX la montaña más alta de América y una de las más altas del mundo. La sección transversal

6. Sobre la historia de bloque diagrama véase Eduardo Martínez de Pisón y Juan Carlos Castañón 2005.

7. William Morris Davis propone un modelo genético para explicar las formas del relieve a través de tres variables explicativas: proceso, estructura y tiempo. El ciclo "ideal" supone cuatro estadios: juventud, madurez, transición y vejez. 
abarca los Andes ecuatoriales del oeste de América del Sur, junto con colindante costa del Pacífico y las tierras bajas amazónicas (Zimmerer, 2011). Sobre el margen derecho de la ladera del Chimborazo se presentan gráficamente los pisos ecológicos, es decir, los diferentes tipos de vegetación según la altura respecto del nivel del mar.

La imagen realizada por Humboldt del volcán Chimborazo es una imagen que fue pensada para circular en ámbitos científicos. En efecto, como destaca Karl Zimmerer, Humboldt tomó mucho cuidado en la producción de esta imagen: trabajó con artistas y dibujantes parisinos que bajo su dirección realizaron bocetos y grabados utilizados para la impresión del mapa del Chimborazo. En el contexto de las reglas y la tradición de los saberes topográficos del siglo XIX esta imagen humboldtiana se inscribe dentro de una serie que podríamos denominar imágenes científicas, tanto por el perfil profesional del autor como por la obra en que la imagen fue incluida. Incluso retrospectivamente, ese perfil del Chimborazo ha sido considerado uno de los primeros mapas temáticos y muy reconocido por la manera innovadora de representar el terreno y la vegetación durante el siglo XIX. Sin embargo, hoy en día, visto desde nuestra propia cultura visual, el mapa del Chimborazo es considerado una obra de arte más que una imagen científica porque comparte códigos estéticos que habitualmente se asocia a la pintura del paisaje.

A pesar de la diferencia en los ámbitos de circulación de ambas imágenes lo cierto es que tanto Humboldt como Pesce logran "ubicar al espectador en una posición imaginaria y abstracta alejada del escenario natural, un punto de vista donde se condensan ideas científicas y desde el cual es posible observar aquello que no es observable en el terreno" (Pimentel, 2004: 12). Esta cita que Juan Pimentel hace sólo para la obra humboldtiana se extiende claramente para el trabajo de Pesce y su utilización de estrategias y lenguajes que hoy se consideran parte de la explicación científica del relieve. Dicho en otras palabras: los bloques-diagramas muestran secciones del terreno que el ojo desnudo (sin la teoría explicativa y sobre el terreno) jamás podría ver. Son precisamente esas convenciones las que nos llevan a pensar que pertenece a una serie de representaciones cientificas $^{8}$ del terreno: a través de ellas reconocemos algo que no se ve a partir de la observación directa y que tampoco se puede ver a partir de prótesis visuales $^{9}$ y que, en cambio, resulta representable, posible y comprensible gracias a un proceso de abstracción (en los casos de las imágenes de la Figura 3, una teoría geológica o biogeográfica) que es prácticamente desarrollada en diversas disciplinas científicas.

Cabe preguntarnos si sería posible mirar la pintura de Pesce como una imagen científica y, al mismo tiempo, mirar el trabajo de Humboldt como una obra de arte. Para ensayar alguna respuesta a esta pregunta es necesario pensar en nuestra manera de mirar las imágenes y en cómo esos modos de mirar varían a lo largo del tiempo. Un lector entrenado en la forma de representar el terreno del siglo XIX preferiría la imagen

8. Utilizamos el término científico sólo a fines prácticos y para oponer al artístico. Porque justamente lo que intentamos poner en discusión es la cientificidad de la imagen. Creemos que lo que hace a una imagen “científica" tiene que ver con el ojo del que mira y no con la imagen en sí.

9. Nos referimos a la utilización de instrumentos que nos permita observar el recorrido de la lava y de chimeneas laterales como en la imagen de Pesce. 
humboldtiana y no entendería un bloque-diagrama como una imagen científica para la representación del volcán. La imagen de Pesce, a pesar de haber sido pensada para circular en el mundo del arte, puede adquirir un nuevo significado en otro contexto, como por ejemplo en la página de un libro escolar: dado que su lenguaje gráfico tiene muchos puntos en común con los esquemas de los perfiles topográficos y geológicos actuales, podría ser utilizada para explicar geológicamente las erupciones volcánicas. De manera similar, la imagen de Humboldt, retirada de su contexto originario- los salones científicos del siglo XIX- y expuesta en un museo o reproducida en un libro de imágenes artísticas también adquiere un significado diferente al que originalmente fue pensada.

En este sentido parece oportuno extrapolar lo que Edney (1992) dice para la imagen cartográfica: "el significado de los mapas no es inherente a la imagen -ni fijo ni estable- sino que los lectores leen el mapa de acuerdo a las convenciones de los discursos particulares en que están situados; el significado de cualquier mapa [imagen] variará por lo tanto entre los lectores, con el tiempo, y entre los discursos"10 (Edney, 1992: 85). Las imágenes por sí solas no nos dicen mucho. Es la mirada de espectador, configurada en torno a un conjunto de convenciones propias de cada cultura visual, y el contexto de circulación de las imágenes las que le otorgan significado. Es decir, la canónica división entre imágenes científicas e imágenes artísticas no alcanza para explicar un gran número de imágenes híbridas que combinan diversos lenguajes gráficos, que evocan tradiciones de saberes variadas y que interpelan a públicos múltiples, entre ellos el público escolar.

\section{Un gris más: la imagen y sus finalidades}

Ya señalamos la importancia del soporte y el contexto de utilización (o de visualización) en la definición de las condiciones de visibilidad de una imagen como didáctica o artística. También, advertimos el modo en que intervienen las convenciones propias de cada cultura visual para mirar las imágenes como científicas o artísticas. Unos años más tarde a la publicación de la fotografía del salón escolar poblado de mapas de 1905, El Monitor de la Educación Común, publicó un artículo titulado El dibujo y los maestros (1915). El autor, un formador de maestros, se esfuerza por distinguir dos facetas -una artística y otra didáctica- del dibujo. El texto, escrito a principios del siglo $\mathrm{XX}$, expone otro criterio frecuentemente utilizado para trazar una delimitación entre las imágenes didácticas y las artísticas, como se advierte en este fragmento:

Ese futuro maestro debe aprender el dibujo, de un modo particularmente muy útil.

Es necesario hacer el distingo entre el artista y el maestro. El primero, como dice Ruskin: es el que pone en sus dibujos "la ternura que inspira el amor y el misterio que inspira la potencia creadora"; el maestro, en cambio, tiene como fin, transmitir conocimiento en forma clara, concisa, exacta y de utilidad para

10. "In other words, the meanings of maps are not inherent to each image - they are not fixed and stable - but are instead read into the maps by their readers according to the conventions of the particular discourses within which the readers are situated; the meaning of any given map will thus vary between readers, over time, and between discourses (Pickles 1992, 2004)" (Edney, 1992: 85). 
la vida. A él nada le importan ni le preocupan las tendencias escolásticas en arte, ni tampoco la ejecución perfecta en el alto sentido artístico. Lo que sí debe saber hacer son esquemas y croquis trazados correctamente, en los que hallará la poderosa ayuda, para aclarar sus exposiciones orales, al mismo tiempo que le resultarán uno de los tantos factores (el más importante) para desarrollar el gusto estético, despertar la animación y provocar una inteligente atención de parte de los niños. (Carlos Martinelli, 1915: 626-627)

La demarcación entre un dibujo artístico y uno didáctico se define aquí por sus características (estética versus precisión) pero sobre todo por su finalidad: la creación en contraposición a la transmisión. En efecto, muchas ilustraciones utilizadas en los libros escolares tienen una estética que las aproximaría más al dibujo artístico. Sin embargo, el diálogo que se establece entre ellas y el texto escolar define una finalidad pedagógica para esas imágenes: con ellas se busca entrenar el ojo de los lectores. Así por ejemplo, la Figura 4 reproduce una doble página de un libro de geografía de principios de siglo XX. El Panorama geográfico (izquierda) se vuelve una imagen didáctica a través de la serie de ejercicios que figuran al pie de la página: cada elemento de la ilustración es enunciado desde el texto de modo tal que los alumnos/lectores establezcan la relación

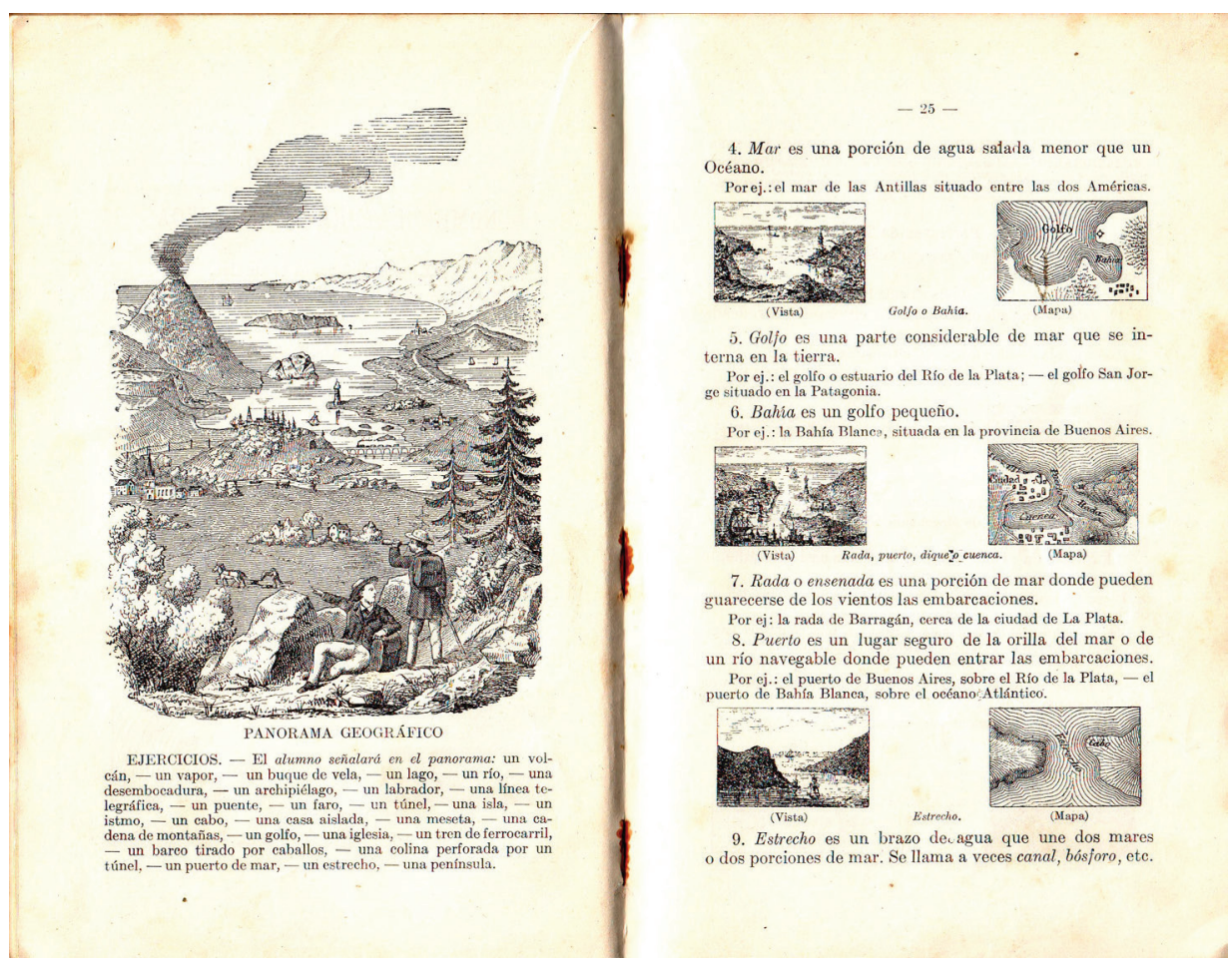

Figura 4. El texto hace de la imagen un objeto de uso escolar.

Fonte: Libro Primero para la Enseñanza Primaria. Buenos Aires: Librería de José Moly. (pp. 24-25).

10 Edición ilustrada con numerosos mapas y grabados. Circa 1910 
entre concepto e imagen. El ejercicio pareciera buscar que los lectores recreen la mirada exploratoria de los dos observadores situados en la imagen en un punto privilegiado de observación. La serie de dípticos ofrece, luego de la explicación de orden conceptual, dos modos de ver (y representar) distintos elementos/accidentes geográficos: la vista, que simula cómo se vería con los propios ojos y el mapa, con una visión cenital.

Podemos pensar que en esta práctica de comparar los elementos del terreno con los de la foto o mapa, clásica en la enseñanza de la geografía de las primeras décadas del siglo XX, la imagen cartográfica se va naturalizando como única representación posible y como consecuencia se vuelve más opaca.

Cuando hablamos de la dimensión opaca de la imagen cartográfica, nos referimos a la aparentemente naturalidad con que la tomamos su representación. Como si aquello que representa es naturalmente de esa manera. No nos cuestionamos la forma que el cartógrafo eligió para el río o para el meandro simplemente lo aceptamos sin cuestionarlo. Luego una vez en el terreno buscamos esa forma es como si la imagen nos impusiera la forma que debemos ver. Esta opacacidad de la imagen tiene un carácter histórico, es decir lo que hoy nos resulta muy transparente no siempre fue así, por ejemplo las alturas no siempre se representaron a partir de números y líneas. Cuando vemos en un mapa un conjunto de líneas cerradas acompañadas con un número que asciende hacia el centro lo relacionamos con una altura tenemos que entender que otro lector no familiarizado con este tipo de representaciones puede que no entienda lo mismo que nosotros (Siracusano, $2008[2005])$.

La finalidad atribuida a la imagen como criterio de clasificación del universo visual recrea la controversia de fines del siglo XIX en torno al arte como búsqueda de la belleza y la ciencia como búsqueda de la verdad (Jones y Galison, 1998). Aunque pueda resultar paradójico, esta contraposición de la imagen didáctica y la artística es contemporánea a la idea que el arte debe formar el gusto y desarrollar una sensibilidad estética, propia de la modernidad (Groys, 2015). En efecto, los museos, las exposiciones, las ferias, los panoramas y los teatros en el siglo XIX comparten la exploración y el ensayo de técnicas de presentación de los objetos para educar los modos de ver (Podgorny y Lopes, 2008). El arte, entonces también se enlaza a ese esfuerzo de modelar la mirada y los demás sentidos. La finalidad de una imagen, como criterio de definición de dos campos de imágenes, deja de ser taxativa y comienza a resultar problemática.

Invitamos al lector a realizar un ejercicio visual más: mire las siguientes tres imágenes e intente descifrar si se trata de imágenes didácticas o artísticas (Figura $5 \mathrm{a}, \mathrm{b}, \mathrm{c}$ ). Indagar su contenido, su soporte, su contexto de circulación y también su arquitectura visual puede aportar algunas claves para problematizar este criterio de demarcación.

El primer árbol es la tapa de la edición francesa de la Encyclopédie de Diderot y le Rond d'Alembert, publicada en 1751. El diseño expone una propuesta de ordenamiento y jerarquización de los campos de conocimiento y también una argumentación acerca de sus conexiones. El árbol traza una estructura genealógica del conocimiento con tres grandes ramas del conocimiento: memoria e historia, razón y filosofía e imaginación y poesía. Cada rama tiene sus frutos que se presentan en círculos de distintos tamaños. 

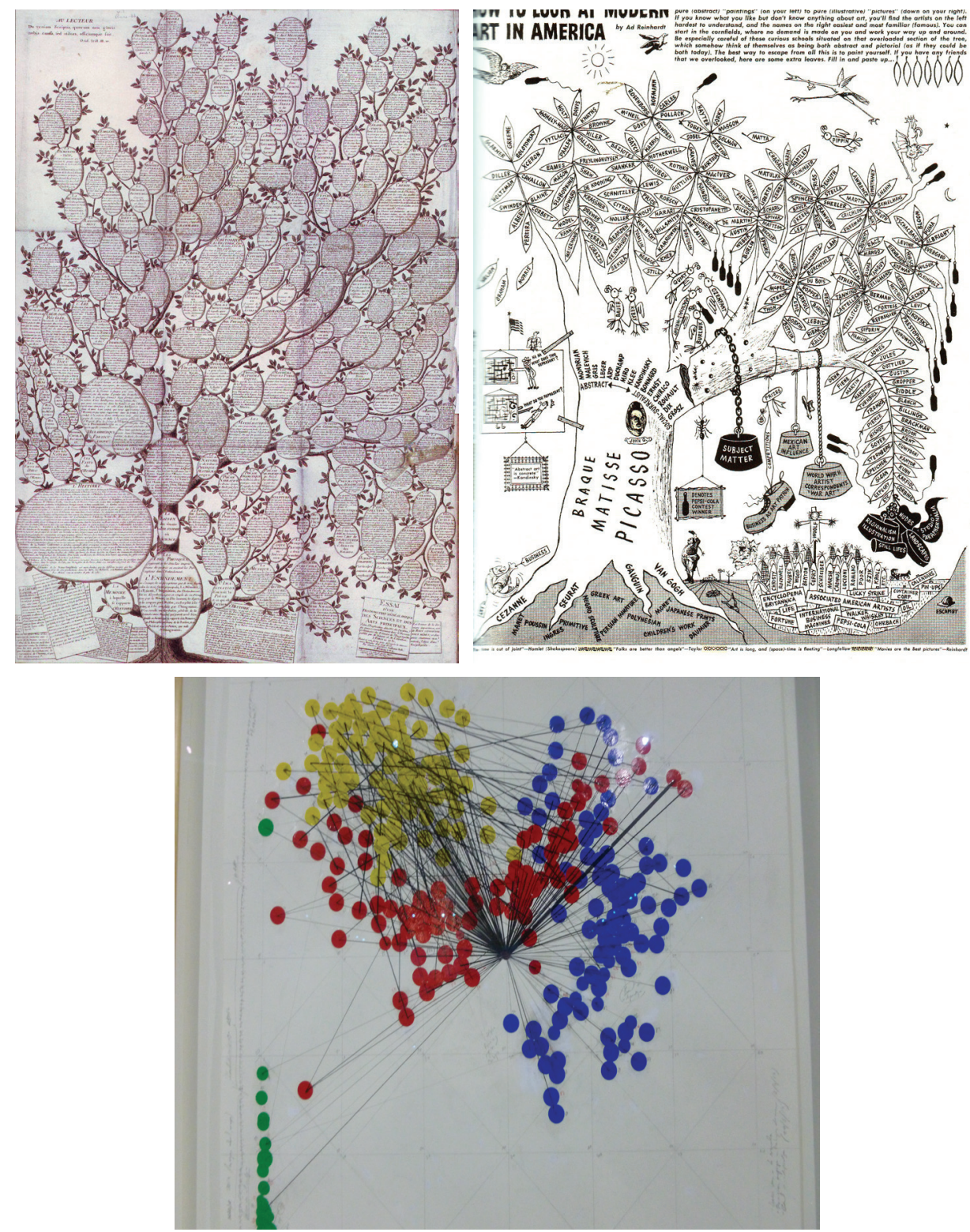

Figura 5. Los árboles y los diagramas: ¿Imágenes híbridas?

Fig.5A. Essai d 'une distribution généalogique des sciences et des arts principaux. Tapa de la edición francesa de la Encyclopédie de Diderot y le Rond d'Alembert, publicada en 1751. Fig. 5B. How To Look At Modern Art In America, 1961. Ad Reinhardt papers, 1927-1968. Archives of American Art, Smithsonian Institution.

Fig. 5C Fotografía de las autoras, fragmento de la obra de Jaime Serra, Un diagrama familiar (2010-2013). Abril 2016. 
El segundo árbol es una viñeta realizada por Ad Reinardt, cuyo título pareciera delinear una clara finalidad educativa cómo mirar el arte moderno en América. La leyenda en el margen superior derecho agrega:

Aquí encontrará una guía a las galerías: un árbol del arte contemporáneo desde
el arte abstracto (a su izquierda) al arte más ilustrativo (a su derecha). Si usted
ya conoce lo que le gusta pero no conoce nada sobre arte, le resultará más difícil
entender los nombres de los artistas a su izquierda, en cambio, le resultará más
fácil y conocido el lado derecho. También puede comenzar en el campo de
maíz, donde no se le exige a usted y puede recorrerlo hacia arriba y hacia sus
contornos.

Este árbol ordena muchísima información (historia del arte en dos dimensiones) con el estilo gráfico de una viñeta y propone así un abordaje crítico, satírico. También deja un espacio abierto (hay hojas en blanco para que los lectores completen con nombres de otros artistas) $)^{11}$.

Finalmente, la fotografía de un fragmento de la obra de Jaime Serra titulada Un diagrama familiar, 2010-2013 y expuesta en la muestra Big Bang Data (Santiago de Chile, 2016). El autor explica que durante un trimestre entre los años 2010 y 2013 realizó un diagrama en el que fue cualificando las relaciones establecidas con los integrantes de su familia. Cada integrante de la familia se presenta como un punto con un color y las modalidades de relación (telefónica, virtual, almuerzo) y temporalidades (mediodía, día) con líneas de distintos grosores. Se trata de una visualización "artística" de datos.

Los árboles-mapa y los diagramas, como lo demuestran estas tres imágenes, son una forma elegante (e incluso bella) de presentar la información y hasta de argumentar. Algunos árboles y diagramas resultan atractivos y ponen en jaque la divisoria entre imagen científica, imagen artística, imagen didáctica. Ellos tienen una finalidad compartida: explicar y educar; facilitar la cognición y promover el entendimiento, hacer visible lo invisible (Lima, 2014). Pero también con estas imágenes se propone crear, seducir los ojos de quien se encuentre con ellas, resultar estéticamente agradables. Si es cierto que estas tres imágenes nos alientan de modo más evidente a encontrar la hibridez en sus finalidades, existen otros registros visuales que también hacen tambalear la aparente solidez de este criterio de demarcación. La fotografía, por ejemplo, ilustra explicaciones científicas, es un método de hacer ciencia pero también incluso la denominada fotografía científica es valorada por sus características estéticas y mirada como una obra de arte (Wilder, 2009) ${ }^{12}$. Los aportes realizados a mediados del siglo XX entre otros por Rudolf Arnheim así como la creciente (aunque no novedosa) producción de imágenes estéticamente bellas que presentan datos y resultan útiles (y no solo destinadas a generar un placer de orden estético) sugieren que no hay ningún atributo propio de la imagen que la defina como una imagen didáctica o como una imagen artística.

11. Encontramos esta viñeta en uno de los libros de Edward Tufte, titulado Beautiful evidence.

12. Wilder se detiene en algunas experiencias artísticas que a partir de las fotografías científicas o de las propias prácticas de investigación en el campo de las ciencias exponen y discuten la aparente transparencia del acto fotográfico en el contexto científico. 
Por otro lado, el arte ya no solo tiene como finalidad conmover nuestros sentidos. Así por ejemplo, el artista chileno Alfredo Jaar decía en una entrevista: "las obras que mejor cumplen su objetivo consiguen precisamente esto: nos ofrecen una experiencia estética, nos informan y nos piden que reaccionemos. Y la profundidad de la reacción dependerá de la capacidad de la obra para conmovernos tanto a través de nuestros sentidos como a través de nuestra razón, combinación muy difícil, y casi imposible de lograr" (citado en Didí-Huberman, 2007: 49). Si estamos de acuerdo que tanto la educación como el arte, tienen la finalidad de presentar otros modos de mirar podríamos indagar qué nos aporta el arte hoy para pensar el encuentro con las imágenes en las culturas escolares.

\section{Pinceladas finales: por otros diálogos entre el arte y las imágenes en el contexto escolar contemporáneo}

Vivimos un período en el que la circulación de las imágenes facilita su reedición, re-apropiación y re-escritura. También, transitamos un período que nos ofrece la posibilidad de encontrarnos con muchas imágenes artísticas más allá de los museos. Un recorrido por muchos salones de clase expone la coexistencia de soportes de registros visuales de distintas épocas: láminas, libros, pizarras, las pantallas de las computadoras personales, y también las pantallas de los celulares de nuestros alumnos. Todavía más: en las últimas décadas en los materiales educativos se han incluido imágenes que no fueron diseñadas con fines didácticos y sin embargo, con ellas se pretende enseñar. En resumen, las nuevas tecnologías y nuestras culturas escolares han extendido las condiciones de visibilidad a un conjunto de imágenes cada vez más vasto. Ante este panorama cabe interrogarnos: ¿Qué es lo que queremos hacer con la imagen? ¿Qué es lo que le pedimos? ¿Qué interrogantes nos permitimos hacerle?

Los artistas y los docentes compartimos un desafío impuesto por nuestra contemporaneidad: hay más gente interesada en producir imágenes que en mirarlas (Groys, 2015). En efecto, nuestros alumnos son más productores de imágenes que nosotros mismos. Ante la proliferación de imágenes, como explica Georges DidíHuberman, "estamos predispuestos a no creer nada de lo que vemos y, finalmente, a no querer ni mirar lo que tenemos ante nuestros ojos" (2007: 42). Esta constatación impone dos interrogantes: ¿Cómo abordar este conjunto de imágenes "didácticas” casi inabarcable? ¿Cómo ampliar las coordenadas de lo visible sin renunciar a reconocer esa "formación facetada" de cada imagen?

En contadas excepciones, las imágenes se disponen aisladamente. Lo más frecuente es que se presenten formando una composición con otras imágenes y palabras. Un conjunto de experiencias artísticas visuales nos interpelan a dar un paso más en la educación visual: ya no solo tenemos que enseñar a hacer las preguntas adecuadas a las imágenes sino también a realizar montajes diversos de imágenes que discutan con la homogeneidad visual que nos propone la cultura contemporánea. El arte y la educación pueden (y no deberían renunciar a) proponer otras selecciones puesto que el acto de seleccionar y montar un orden visual constituye un acto político y a la vez poético. 
Aquí nos resulta particularmente fructífero traer la idea de composición/ montaje. Inspirado en la obra del dramaturgo Bertolt Brecht, titulada Arbeitsjournal, Georges Didí-Huberman (2008) discute la noción de montaje de los textos y de las imágenes, buscando resaltar el valor argumentativo de la exposición de las imágenes ${ }^{13}$.

Pero ¿por qué había sido necesario recortar esas imágenes y montarlas e otro orden, es decir, desplazarlas a otro nivel de inteligibilidad, de legibilidad? Un documento encierra al menos dos verdades, la primera de las cuales siempre resulta insuficiente. (Georges Didí-Huberman, 2008: 41).

Entendemos por composición la disposición de las imágenes en una secuencia (no necesariamente lineal) que funciona como ordenador y que propone vínculos - más o menos explícitos- con el texto y con las otras imágenes ${ }^{14}$. La composición también incluye jerarquías, yuxtaposiciones, interrupciones, vacíos, espacios en blanco ${ }^{15}$ que intervienen en la construcción de la narrativa ofrecida y en nuestro modo de mirar las imágenes.

Se trata de descomponer el montaje del corpus de análisis y recomponer o re-montar (Didí-Huberman, 2008: 21) las imágenes en otro orden, otra secuencia, e inclusive con otras palabras. Se trataría de un montaje que, como sucede con la edición de una película, resulta en modos particulares de hacer mirar las imágenes. Desde esta perspectiva de análisis, las imágenes ya no solo funcionan por su alianza con las palabras sino que también funcionan de un modo particular en tanto elementos integrantes de una composición.

Si "la música se convierte en música porque el oyente la escucha como tal, de aquí se infiere que hacer música no es sólo juntar sonidos en forma organizada sino también asegurar que esos sonidos dejen una huella" (Frith, 2014: 185), podríamos pensar que, de modo análogo, las imágenes se convierten en imágenes cuando encuentran quien las mira. Tal vez, el diálogo entre arte e imágenes en contextos escolares además de evidenciar la debilidad de las fronteras entre imágenes artísticas y didácticas nos invita a atrevernos a imaginar otras narrativas para las mismas imágenes. Todavía más: nos desafía a promover en nuestros alumnos la posibilidad de imaginar otros montajes que los (y nos) interpelen en el contexto escolar, que los (y nos) afecten dejando huellas en nuestra experiencia visual.

13. Es interesante señalar que esta idea también merodea el campo musical. El Keller Quartet propone combinar obras o géneros, que usualmente no son interpretados en un mismo concierto, con el propósito de evidenciar los diálogos que se establecen entre estas obras y los efectos que provocan estas combinaciones en los modos de escuchar cada pieza. Así por ejemplo, en el concierto realizado en Agosto de 2014 en el Teatro Colón de Buenos Aires combinaron El arte de la fuga de J. S. Bach y las obras recientes del compositor húngaro György Kurtág (1926). Quienes estuvimos allí escuchamos una nueva obra en esa combinación de modernidad y revisión del pasado.

14. Si bien con mayor preocupación en el diseño visual que en la idea de composición visual, Edward Tufte analiza la disposición adyacente de imágenes, particularmente apropiada para destacar y detectar contrastes y correspondencias (Tufte, 2012).

15. Tomamos la idea de la importancia del espacio en blanco en tanto campo que promueve las conexiones sin pre-establecerlas del trabajo de Bender, J. y Marrinan M. (2010). 


\section{Referencias}

ANESI, José. Orígenes y evolución del mapa geográfico. El Monitor de la Educación Común. Año LXII. Octubre, Noviembre y Diciembre 1943. Nros 850, 851, 852. Pp. 4071. Consejo Nacional de Educación. Buenos Aires, 1943.

ARNHEIM, Rudolf. Visual thinking. Berkeley: University of California Press, 1997.

BENDER, John. y MARRINAN, Michael. The culture of diagram. California: Standford University Press, 2010.

BERTOLA, Chiara. Mona Hatoum. Buenos Aires: Fundación Proa, 2015.

DE DIEGO, Estrella. Contra el mapa. Madrid: Siruela, 2008.

DIDI-HUBERMAN, Georges. La emoción no dice "yo". Diez fragmentos sobre la libertad estética. In: Schweizer Nicolás (dirección), Alfredo Jaar. La política de las imágenes. Santiago de Chile: Ediciones metales pesados, 2007. p. 39-67.

DIDI-HUBERMAN, Georges. Cuando las imágenes toman posición. Madrid: Antonio Machado Libros, 2008.

EDNEY, Matthew. Mapping Empires, Mapping Bodies: Reflections on the Use and Abuse of Cartography. Treballs de la Societat Catalana de Geografia, núm. 63, 83-104. 2007.

FRITH, Simon. Ritos de la interpretación. Sobre el valor de la música popular. Buenos Aires: Paidós, 2014.

GIUNTA, Andrea. Escribir las imágenes. Ensayos sobre arte argentino y latinoamericano. Buenos Aires: Siglo XXI, 2011.

GROYS, Boris. Volverse público. Las transformaciones del arte en el ágora contemporánea. Buenos Aires: Caja Negra, 2015.

HERMANOS DE LAS ESCUELAS CRISTIANAS. Geografía, Libro Primero para la Enseñanza Primaria. Buenos Aires: Librería de José Moly. Décima Edición ilustrada con numerosos mapas y grabados. Circa 1910.

JACOB, Christian. The sovereign map. Theoretical approaches in cartography throughout history. Chicago: The University of Chicago Press, 2006.

JONES, Caroline y GALISON, Peter. Picturing science, producing art. London: Routledge, 1998.

LIMA, Manuel. The book of trees. Visualizing branches of knowledge. New York: Princeton Architectural Press, 2014.

MARTINELLI, Carlos. El dibujo y los maestros. El Monitor de la Educación Común. Año 33, Tomo 55. Consejo Nacional de Educación, 1915. p. 625-631.

MARTINEZ DE PISON, Eduardo y CASTAÑON ALVAREZ,Juan Carlos. Historia del bloque-diagrama en España. In:ORTEGA CANTERO, Nicolás(editor) Imágenes del paisaje, Editor, Fundación Duque de Soria UAM, Madrid, 2005. p 101-147. 
PIMENTEL, Juan. El Volcán Sublime: Humboldt desde el Chimborazo.En: PIMENTEL, Juan. Testigos del mundo. Ciencia, literatura y viajes en la Ilustración. Madrid: Marcial Pons, 2003. p.179-210.

PIMENTEL, Juan. Cuadros y escrituras de la Naturaleza.En Asclepio, Vol. L VI-2. 2004, p.7-23.

PODORNGY, Irina y LOPES Maria. El desierto en una vitrina. Museos e historia natural en la Argentina, 1810-1890. México D.F: Editorial Limusa, 2008.

RAISZ, Erwin. Cartografia. Barcelona: Omega, 1959 [1953].

RICOEUR. Paul. Sobre la Traducción, Buenos Aires: Paidós, 2004.

SIRACUSANO, Gabriela. El poder de los colores. De lo material a lo simbólico en las prácticas culturales andinas. Siglos XVI- XVIII. Buenos Aires: FCE. 2005.

TORRES, Pedro. La ilustración de las lecciones: rompecabezas geográfico. El Monitor de la Educación Común. Año XXV, Nro 391, Tomo XXI. Agosto 1905. Consejo Nacional de Educación. 1905. p. 190-194.

TUFTE, Edward. Beautiful evidence. Cheschire: Graphis Press LLC, 2006.

TUFTE, Edward. Visual explanations. Images and quantities, evidence and narrative. Cheschire: Graphic Press LLC, 2012.

VILLARINO DE CARRIL, María. Manual de Geografía Física y Política. Aprobado por el Gobierno Nacional para el uso de los Colegios y Escuelas de la República Argentina y por la Junta de Educación de la Provincia de San Juan. Buenos Aires: Imprenta y Librería de Carlos Casa Valle, 1875.

VEDÍA, Juan Manuel. Los mapas. Estampas y demás objetos de enseñanza. El Monitor de la Educación Común. Consejo Nacional de Educación. N 357. 1902. p. 945-954.

WECHSLER, Diana. Vik Muniz Buenos Aires. Caseros: Universidad Nacional de Tres de Febrero, 2015.

WILDER, Kelley. Photography and science. London: Reaktion Books, 2009.

ZIMMERER, Karl. Mapping mountains. In: DYN, Jordana y OFFEN, Karl (editors) Mapping Latin America. Chicago: The University of Chicago Press, 2011.p.125-133.

Verónica Carolina Hollman

Doctora en Ciencias Sociales de la FLACSO Argentina, Master of Arts de la University of British Columbia (Canadá), Profesora y Licenciada en Geografía de la Universidad Nacional del Comahue (Argentina). Actualmente es investigadora adjunta del Consejo Nacional de Investigaciones Científicas y Técnicas en el Instituto de Geografía "Romualdo Ardissone" (Universidad de Buenos Aires) y profesora en la Universidad del Centro de la Provincia de Buenos Aires.

E-mail: vhollman@gmail.com 
Malena Malena Mazzitelli Mastricchio

Licenciada en Geografía de la Universidad de Buenos Aires y doctoranda en la misma universidad. Actualmente es profesora de la Universidad Nacional de la Plata y la Universidad Autónoma de Entre Ríos.

Universidad de Buenos Aires. Faculdade de Filosofia y Letras. Instituto de Geografia. Puán 480 Tercer Piso- oficina 330. Buenos Aires, Argentina.

E-mail: mastricchiomalena@gmail.com

Recebido para publicação em março de 2016 Aprovado para publicação em junho de 2016 